Eduardo de Britto Perez

Otimização do processo de secagem na manufatura de fitas adesivas

Dissertação de Mestrado

DEPARTAMENTO DE ENGENHARIA MECÂNICA Programa de Pós-Graduação em Engenharia Mecânica

RIO DE JANEIRO

Março de 2004 


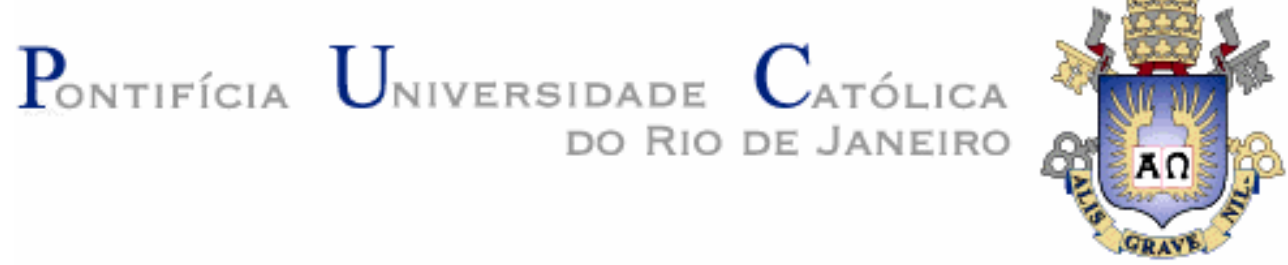

Eduardo de Britto Perez

Otimização do processo de secagem na manufatura de fitas adesivas

Dissertação de Mestrado

Dissertação apresentada ao Programa de Pós-graduação em Engenharia Mecânica da PUC-Rio como requisito parcial para obtenção do título de Mestre em Engenharia Mecânica.

Orientador: Prof. Dr. Márcio da Silveira Carvalho

Rio de Janeiro

Março de 2004 
Eduardo de Britto Perez

\title{
Otimização do processo de secagem na manufatura de fitas adesivas
}

Dissertação apresentada como requisito parcial para obtenção do grau de Mestre pelo Programa de Pósgraduação em Engenharia Mecânica da PUC-Rio. Aprovada pela Comissão Examinadora abaixo assinada.

\author{
Prof. Márcio da Silveira Carvalho \\ Orientador \\ Departamento de Engenharia Mecânica - PUC-Rio
}

Prof. Paulo Roberto de Souza Mendes Departamento de Engenharia Mecânica - PUC-Rio

Prof. Luis Fernando Alzuguir Azevedo Departamento de Engenharia Mecânica - PUC-Rio

Dr. Marcelo Catanoce Gandur 3M do Brasil Ltda

Prof. José Eugenio Leal Coordenador Setorial do Centro Técnico Científico - PUC-Rio 
Todos os direitos reservados. É proibida a reprodução total ou parcial do trabalho sem autorização da universidade, do autor e do orientador.

\section{Eduardo de Britto Perez}

Graduou-se em Engenharia de Produção Mecânica na Universidade de São Paulo, Campus de São Carlos, em 1995. Trabalha na 3M do Brasil Ltda desde 1996, atuando como Engenheiro de Processos nas áreas de revestimento, polimerização, secagem e corte de fitas adesivas diversas.

Ficha Catalográfica

Otimização do processo de secagem na manufatura de fitas adesivas / Eduardo de Britto Perez; orientador: Márcio da Silveira Carvalho. - Rio de Janeiro: PUC, Departamento de Engenharia Mecânica, 2004.

177 f. : il. ; $30 \mathrm{~cm}$

Dissertação (mestrado) - Pontifícia Universidade Católica do Rio de Janeiro, Departamento de Engenharia Mecânica.

Inclui referências bibliográficas.

1. Engenharia mecânica - Teses. 2. Secagem. 3. Soluções poliméricas. 4. Substratos impermeáveis. 5. Simulação numérica. 6. Otimização. I. Carvalho, Márcio da Silveira. II. Pontifícia Universidade Católica do Rio de Janeiro. Departamento de Engenharia Mecânica. III. Título. 
Para minha esposa, Simoni, pelo apoio e confiança de todas as horas. 


\section{Agradecimentos}

A Deus.

Ao meu orientador, Professor Márcio da Silveira Carvalho, pelo apoio e parceria na realização deste trabalho.

A CAPES e PUC-Rio, pelos auxílios concedidos, sem os quais este trabalho não poderia ter sido realizado.

À $3 \mathrm{M}$ do Brasil, pela oportunidade de desenvolver este trabalho e aumentar minha contribuição.

A Francisco Martins Neto, que conseguiu viabilizar a realização deste trabalho abrindo um precedente para novos projetos de parceria entre a $3 \mathrm{M}$ do Brasil e a PUC-Rio.

A Newton Albuquerque e Gláucio Magnusson, por acreditarem nos benefícios deste projeto e manterem sua continuidade.

À minha querida esposa, Simoni, pelo carinho, compreensão e apoiou de todas as horas.

Aos meus pais, Sr. João e D. Nadir, pela educação e incentivo na minha juventude.

Aos professores que participaram da banca examinadora.

Aos meus irmãos, amigos e familiares que contribuíram e que de alguma forma me incentivaram. 


\section{Resumo}

Perez, Eduardo de Britto; Carvalho, Márcio da Silveira. Otimização do processo de secagem na manufatura de fitas adesivas. Rio de Janeiro, 2004. 177p. Dissertação de Mestrado - Departamento de Engenharia Mecânica, Pontifícia Universidade Católica do Rio de Janeiro.

O processo de manufatura de fitas adesivas geralmente envolve uma etapa de retirada dos solventes presentes na solução revestida e formação de uma camada de material semi-sólido sobre um substrato apropriado.

Devido a alta espessura de adesivo requerida no produto final e a alta concentração de solventes característica da solução revestida, a secagem se torna, muitas vezes, o gargalo do processo produtivo. Ganhos de produtividade em linhas que podem produzir centenas de milhares de metros quadrados de fita adesiva por mês são importantes para viabilizar incrementos na oferta ou redução dos custos operacionais.

Esta dissertação apresenta a análise do processo de secagem de soluções poliméricas revestidas sobre substratos impermeáveis através do desenvolvimento de um modelo matemático para representar os fenômenos de transferência de calor e massa. Também propõe uma metodologia para atingir ganhos de produtividade utilizando um programa computacional especialmente desenvolvido para simulação do processo de secagem.

A utilidade da metodologia e da simulação é demostrada por um estudo de caso realizado na manufatura de fitas adesivas da $3 \mathrm{M}$ do Brasil.

\section{Palavras-chave}

Secagem; adesivos; soluções poliméricas; substratos impermeáveis; simulação numérica; otimização. 


\section{Abstract}

Perez, Eduardo de Britto; Carvalho, Márcio da Silveira. Optimization of drying process in the manufacturing of adhesive tapes. Rio de Janeiro, 2004. 177p. MSc. Dissertation - Departamento de Engenharia Mecânica, Pontifícia Universidade Católica do Rio de Janeiro.

In the manufacturing process of adhesive tapes usually there is a step where the solvents of solution are evaporated in order to allow the formation of a semisolid layer of material over a suitable substrate.

As the final product requires high coating weight and solvent concentration on adhesive solution is high as well, the drying becomes, most of the time, the constraint of the overall process. Productivity increase on machines that can produce hundred of thousands of square meters of adhesive tapes per month can represent additional sale volumes or possibility to reduce operating costs.

This dissertation presents the analysis of drying process of polymeric solutions coated over impermeable substrates through the development of a mathematical model to represent the heat and mass transfer. It also proposes a methodology to achieve productivity increases using a computer code specially developed to simulate the drying process.

The power of this methodology and of the computer-aided simulation is showed by a case study in the manufacturing department of adhesive tapes at $3 \mathrm{M}$ Brazil.

\section{Keywords}

Drying process; adhesives; polymer solution; impermeable substrates; computer-aided simulation; optimization. 


\section{Sumário}

1. Introdução 11

$\begin{array}{ll}\text { 1.1. O processo de revestimento } & 13\end{array}$

2. Fundamentos do processo de secagem 18

2.1. Modelo 20

2.1.1. Transferência de massa da fase líquida para a fase gasosa $\quad 21$

2.1.1.1. Condições de contorno para a equação da conservação das espécies químicas 26

2.1.2. Equilíbrio de fases 28

2.1.3. Atividade dos componentes em uma solução 31

2.1.4. Temperatura de formação de bolhas 33

2.1.5. Transferência de calor 34

2.1.6. Analogia entre coeficientes de transferência de calor e massa 35

2.1.7. Coeficientes de difusão 36

2.1.8. Difusão viscosa, elástica e viscolelástica 40

2.1.9. Sistema completo de equações do modelo de secagem 43

2.2. Método de solução 44

3. Ferramentas para análise do processo de secagem 50

3.1. Bancada de testes 51

3.1.1. Descrição da bancada de testes 53

3.1.2. Operação da bancada de testes 55

3.2. Simulador numérico $\quad 57$

3.2.1. Gráficos fornecidos pelo simulador 58

3.2.2. Validação 63

3.3. Observação do processo 66

4. Otimização do processo de secagem 68

4.1. Metodologia para otimização do processo de secagem 69

4.2. Estudo de caso 71 
Sumário (continuação)

5. Conclusão 80

6. Referências bibliográficas 82

7. Apêndice $\quad 85$

7.1. Estrutura de dados $\quad 85$

$\begin{array}{ll}\text { 7.2. Código Fortran } & 91\end{array}$ 


\section{Lista de figuras}

Figura 1 - Método de cobrimento com vazão pré-fixada 14

Figura 2 - Método de cobrimento com vazão pós-fixada 14

Figura 3 - Estufa de secagem com fluxo paralelo 15

Figura 4 - Estufa de secagem tipo impingiment jets 15

Figura 5 - Estufa de secagem tipo air flotation 16

Figura 6 - Gráfico típico do processo de secagem 19

Figura 7 - Esquema de secagem da camada de líquido sobre substrato 20

Figura 8 - Esquema do balanço de massa na interface líquido-vapor 26

Figura 9 - Esquema do sistema constituído por 2 fases em equilíbrio 28

Figura 10 - Esquema da bancada de teste 52

Figura 11 - Bancada de teste para simulação do processo de secagem 52

Figura 12 - Vista interna da balança 53

Figura 13 - Gráfico do peso de solvente 56

Figura 14 - Gráfico da temperatura da solução $\quad 57$

Figura 15 - Gráfico de solvente residual $\quad 59$

Figura 16 - Gráfico da temperatura de formação de bolhas $\quad 60$

Figura 17 - Gráfico da concentração de solvente 61

Figura 18 - Gráfico do gradiente de concentração 62

Figura 19 - Gráfico da espessura do revestimento 63

Figura 20 - Gráfico de solvente residual $\quad 65$

Figura 21 - Gráfico da espessura do revestimento 65

Figura 22 - Gráfico de temperatura do revestimento 66

Figura 23 - Gráfico do perfil de temperatura da estufa 73

Figura 24 - Determinação do coeficiente de transferência de calor $\quad 74$

Figura 25 - Gráfico de solvente residual $\quad 75$

Figura 26 - Gráfico de solvente residual $\quad 76$

Figura 27 - Gráfico da temperatura de formação de bolhas 77

Figura 28 - Gráfico de solvente residual $\quad 78$

Figura 29 - Gráfico da temperatura de formação de bolhas 79 